\title{
Position Sensorless Control for an Interior Permanent Magnet Synchronous Motor SVM Drive with ANN Based Stator Flux Estimator
}

\author{
Kalyan Kumar Halder, Naruttam Kumar Roy and B.C. Ghosh
}

\begin{abstract}
An Interior Permanent Magnet Synchronous Motor (IPMSM) drive fed by Space Vector Modulated (SVM) inverter without rotor position sensor is proposed in this paper. The control system estimates the motor stator flux and its position through a Real Time Recurrent Neural Network (RTRNN). The RTRNN is trained off-line to estimate stator flux from the speed error and stationary $\alpha$ - and $\beta$ - axis current components obtained through Park's transformation. Vector control of the motor is achieved through command torque and magnetizing current components generation and necessary transformations. The estimated flux and rotor angle are found to match accurately with their corresponding actual values. A Proportional plus Integral (PI) controller is used to control the motor variables in closed loop. The effectiveness of the drive system is tested for different operating conditions. The proposed system is found to work satisfactorily under these conditions and perturbations of parameters.
\end{abstract}

Index Terms-PI controller, Park's transformation, real time recurrent neural network, space vector modulation, and sensorless control.

\section{INTRODUCTION}

Interior permanent magnet motors are recently introduced in industries and domestic appliances for their large torque/weight ratio and constant operating speed with high performance [1]-[6]. Both the constant torque and field weakening modes of operation are studied in detail in [1]. The authors of this paper describe four quadrant operation of the drive system implemented in a microprocessor-based system. Fuzzy logic and four switch (IGBT) converter based IPMSM drive is described in [2]. Digital Signal Processor (DSP) with hysteresis current control is used for their drive system implementation. The same authors apply Fuzzy Logic Control (FLC) to achieve indirect vector control of IPMSM [3]. A modified current control mechanism for VSI-fed IPMSM drive is introduced in [4]. DSP environment is used for practical implementation in this paper. A detailed simulation study and microprocessor-based implementation

Manuscript received July 29, 2009.

Kalyan Kumar Halder is with the department of Electrical and Electronic Engineering of the Khulna University of Engineering and Technology, Khulna, Bangladesh (corresponding author to provide phone: +880-1710752236; e-mail: kalyan kuet@ yahoo.com).

Naruttam Kumar Roy and B.C. Ghosh are with the department of Electrical and Electronic Engineering of the Khulna University of Engineering and Technology, Khulna, Bangladesh (e-mail: nkroy@ yahoo.com, bcg@eee.kuet.ac.bd). is proposed in [5] for application of IPMSM in vehicle. Simple current control mechanism is shown to work effectively in this paper. Maximum torque/ampere control is shown in [6].

Interior permanent magnet motors has q-component inductance, $\mathrm{L}_{\mathrm{q}}$ higher than the d-component, $\mathrm{L}_{\mathrm{d}}$ that requires proper modeling for controller design. A detailed analysis of IPM lumped parameter model starting from variable inductance and mutual coupling is presented in [7]. The paper shows the $\mathrm{d}-\mathrm{q}$ equivalent circuit and describes methodology to measure the lumped parameters of the machine. Machine inductances based on angle dependent reluctances are considered in [8] for dynamic analysis. Simulated results those comply with their proposal are shown in this paper.

Normally, IPM motors are of small size and have applications in low power converting systems. The cost of drives therefore should be kept as small as possible. The drive system avoids position and speed sensors are shown in [9]-[11]. IPM motors posses magnetic saliency that introduces harmonics in the motor current. This phenomenon is introduced in [9] to find out position and speed of the IPM drive. An extended induced voltage model based sensing of back emf and rotor position is presented in [10]. It uses a position error estimator to calculate speed and rotor position. A sliding mode observer based estimation of back emfs along stationary mutually perpendicular reference frames is shown in [11]. The estimated back emfs are then used to find out the rotor position.

Interior permanent magnet synchronous motors require position sensors with the motor to detect the rotor field position. Generally, resolvers or shaft encoders are used for this purpose. This paper proposes a rotor position estimator using stator flux components based on RTRNN. The stator flux components along stationary mutually perpendicular axes are used to calculate instantaneous position of the rotor. Space vector modulation technique is used to reduce the ripple in torque.

\section{MATHEMATICAL MODEL}

The flux of permanent magnet in an IPM machine is assumed to act along d-axis of synchronously rotating frame. The stator voltages and currents act along the physical symmetric a-, b-, c-, coils represented as stationary axes. The torque and magnetizing current components $i_{t}$ and $i_{m}$ respectively, act along mutually perpendicular axes. The 
stationary axes a-, b-, c-, their two phase equivalents $\alpha-, \beta-$, and the rotating axes are shown in Fig. 1. In this representation $\delta$ is the torque angle and $\psi$ is the instantaneous angle of the reference pole of IPMSM.

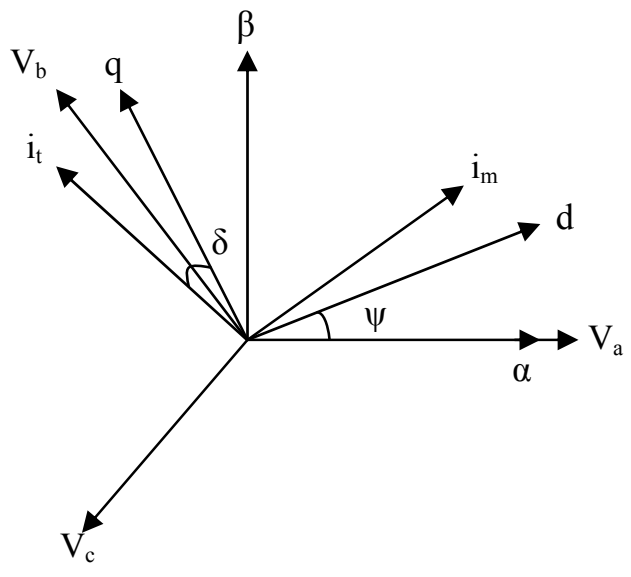

Fig. 1 Stationary and rotating axes of IPMSM

The mathematical equations of the IPMSM motor in $d-q$ axes are written below [7]

$$
\begin{aligned}
& v_{q}=R i_{q}+p L_{q} i_{q}+\omega_{r} \psi_{f}+\omega_{r} L_{d} i_{d} \\
& v_{d}=R i_{d}+p L_{d} i_{d}-\omega_{r} L_{q} i_{q}
\end{aligned}
$$

Flux Linkages along the fictitious d- and q-axis are:

$$
\begin{aligned}
& \lambda_{q}=L_{q} i_{q} \\
& \lambda_{d}=\psi_{f}+L_{d} i_{d}
\end{aligned}
$$

The developed electromagnetic torque is written as:

$$
T_{e}=\frac{3 P_{p}}{2}\left(\psi_{f} i_{q}+\left(L_{d}-L_{q}\right) i_{d} i_{q}\right)
$$

The torque balance equation for the motor speed dynamics is given by

$$
T_{e}=T_{L}+J_{m} p \omega_{m}+B_{m} \omega_{m}
$$

\section{Proposed CONTROL SCHEME}

A control scheme proposed to implement the SVM based vector controlled IPMSM drive is shown in Fig. 2. The high performance control strategy is implemented in closed loop using PI controller in speed loop. The speed error is processed to generate the torque producing component of the stator current $\left(i_{t}{ }^{*}\right)$. The torque angle $\delta$ is a function of $\left(i_{t}{ }^{*} / i_{m}{ }^{*}\right)$ and in this study is:

$\delta=\tan ^{-1}\left(\frac{i_{t}^{*}}{i_{m}^{*}}\right)$

The $\mathrm{d}$ - and $\mathrm{q}$ - axis reference current components are formulated as follows [12]:

$i_{d}^{*}=i_{m}^{*} \cos \delta-I_{t}^{*} \sin \delta$

$i_{q}^{*}=i_{t}^{*} \cos \delta+I_{m}^{*} \sin \delta$

The reference voltage components $V_{d}{ }^{*}$ and $V_{q}{ }^{*}$ are calculated using (1) and (2). The reference voltage vector $u^{*}$ and the inverter switching time are calculated using the formula presented in [13].

If $\gamma$ is the angle between the resultant voltage vector and $\mathrm{q}$-axis then

$$
\gamma=\tan ^{-1}\left(\frac{V_{q}^{*}}{V_{d}^{*}}\right)
$$

If $\psi$ is the angle of resultant stator flux with $\alpha$ - axis then

$$
\psi=\tan ^{-1}\left(\frac{\lambda_{\beta s}}{\lambda_{\alpha s}}\right)
$$

Estimated angle of voltage vector,

$$
\theta=\gamma+\psi
$$

where, the symbols have their usual meanings.

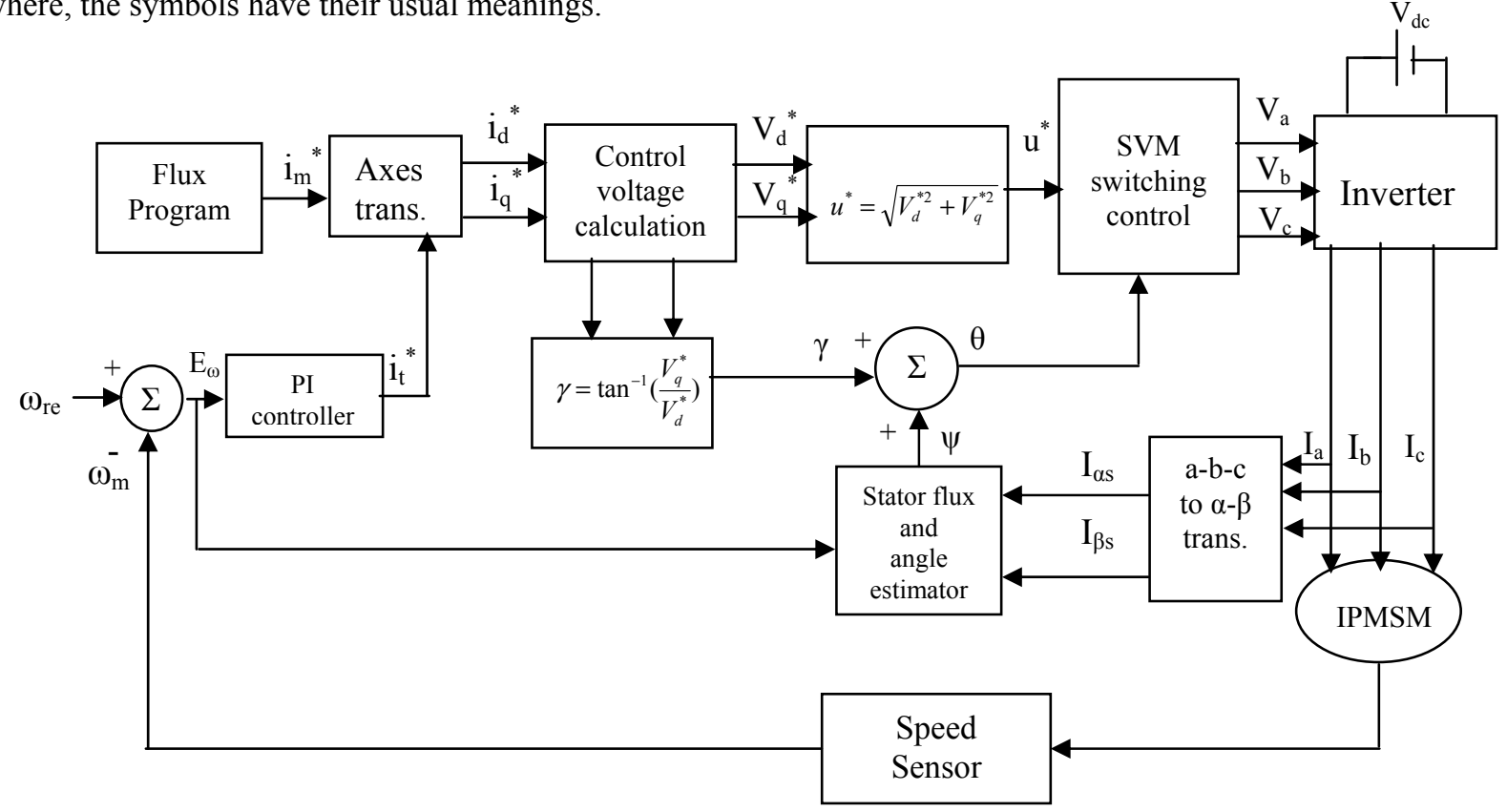

Fig. 2 Proposed Control Scheme of the IPMSM 


\section{REAL TIME RECURRENT NEURAL NETWORK (RTRNN) BASED STATOR FLUX ESTIMATION}

In the proposed algorithm stator flux components are estimated from stationary $\alpha-, \beta$ - axis stator currents and speed error, $E_{\omega}$. An equivalent RTRNN is then proposed which results in the following matrix equation [14]:

$$
\begin{aligned}
& {\left[\begin{array}{l}
\lambda_{\alpha s}(k+1) \\
\lambda_{\beta s}(k+1)
\end{array}\right]=\left[\begin{array}{cc}
W_{11 p} & 0 \\
0 & W_{22 p}
\end{array}\right]\left[\begin{array}{l}
\lambda_{\alpha s}(k) \\
\lambda_{\beta s}(k)
\end{array}\right]+\left[\begin{array}{l}
W_{11} \\
W_{21}
\end{array}\right] i_{\alpha s}(k)} \\
& +\left[\begin{array}{l}
W_{12} \\
W_{22}
\end{array}\right] i_{\beta s}(k)+\left[\begin{array}{l}
W_{13} \\
W_{23}
\end{array}\right] E_{\omega}(k)
\end{aligned}
$$

where $W_{11 p}, W_{22 p}, W_{11}, W_{22}$ etc. are the weights of the RTRNN, which is shown in Fig. 3.

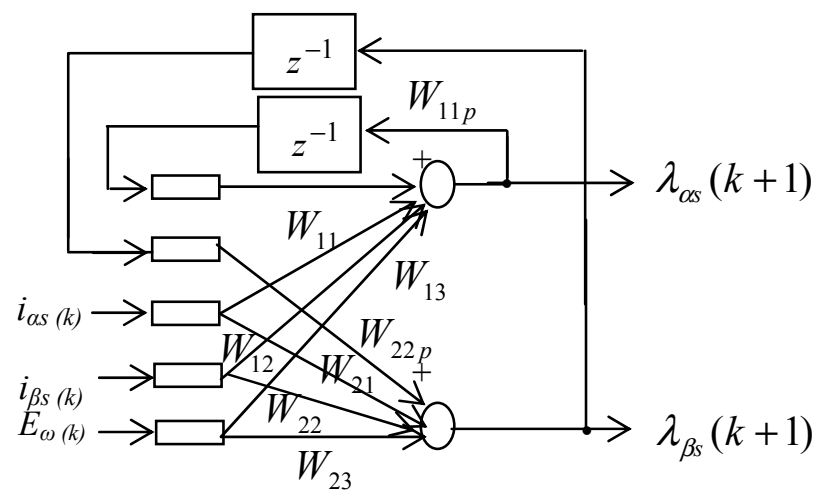

Fig. 3 Stationary $\alpha$ - and $\beta$-axis stator flux estimation by Real Time Recurrent Neural Network (RTRNN)

\section{Simulation Results}

The proposed control scheme was tested by simulation in a Pentium-based PC with C++ environment. Solution of differential equations was carried out using $\mathrm{R}-\mathrm{K} 4^{\text {th }}$ order method. The rating and motor parameters used in this simulation are given in Appendix. The space vectors generated with different switching sequences are used to obtain phase voltages. The sampling time interval is $5 \mu \mathrm{s}$. The stator phase voltages are shown in the Figs. 4(a), (b) \& (c) respectively.

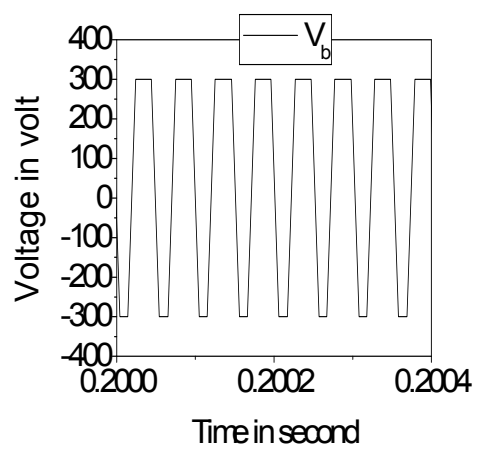

(b)

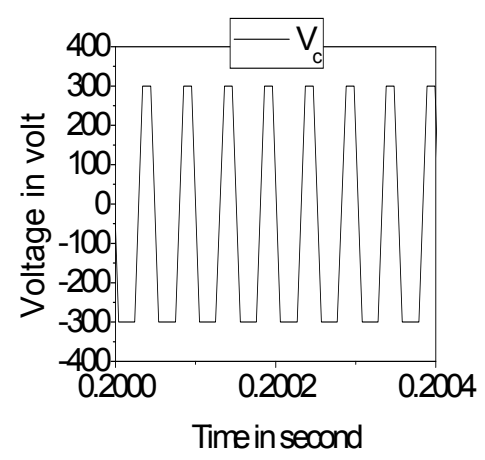

(c)

Fig. 4 Stator voltages for (a) phase $-a$, (b) phase $-b$, (c) phase $-c$.

\section{A. Performance of RTRNN to Estimate Stator Flux and Rotor Angle}

The control system and machine model was simulated simultaneously to visualize the accuracy of the RTRNN flux estimator. The RTRNN was trained off-line under different operating conditions with the exact values obtained from the mathematical model. The estimated and actual values of $\alpha-\&$ $\beta$-axis stator flux components are shown in Figs. 5(a) and 5(b). Position of the rotor is estimated using these flux components and applying to (11). A comparison of estimated value with the actual position from an arbitrary reference is indicated in Fig. 5(c). Perfect matching of the values can be visualized from this figure that indicates the acceptability of the RTRNN to obtain the flux of the IPMSM.

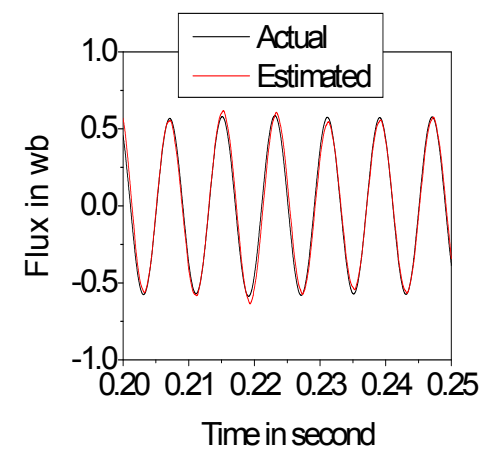

(a)

(a) 


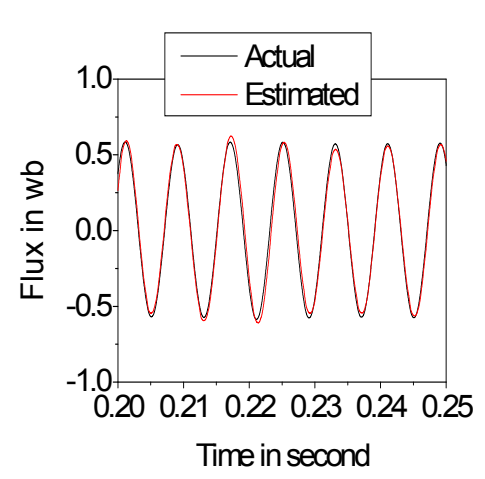

(b)

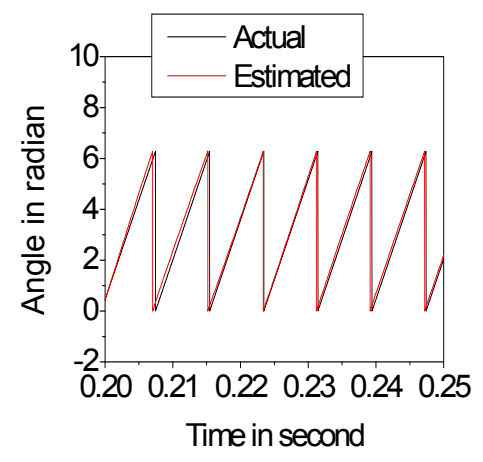

(c)

Fig. 5 (a) $\alpha$-axis components of estimated and actual stator flux, (b) $\beta$-axis components of estimated and actual stator flux, and (c) Estimated and actual rotor angle for the IPMSM drive.

\section{B. Starting Performance of IPMSM drive}

The motor was started with a command speed of $955 \mathrm{rpm}$ from standstill condition. Fig. 6(a) shows the simulated speed response of the drive. It is observed that this drive follows the command speed very fast and reaches the set value at $\mathrm{t}=0.20 \mathrm{~s}$. Fig. 6(b) shows the developed torque that oscillates around the load torque when the motor reaches the set speed. It is noticed that higher electromagnetic torque is generated during the motor acceleration. Some pulsations in electromagnetic torque is noticed which is due to switching voltage disturbances of the devices with SVM.

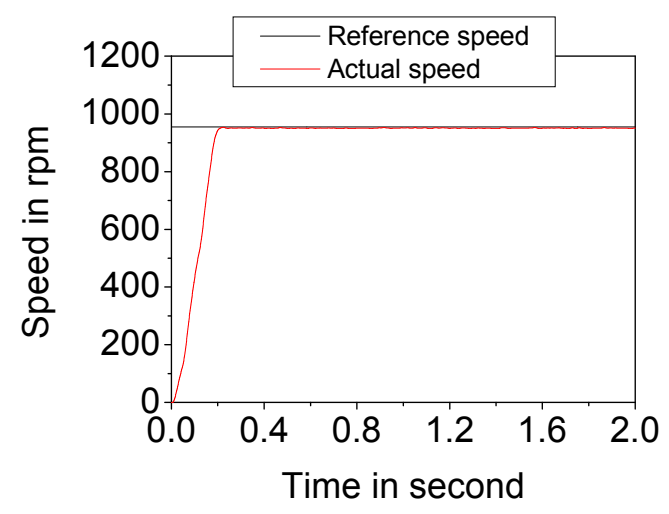

(a)

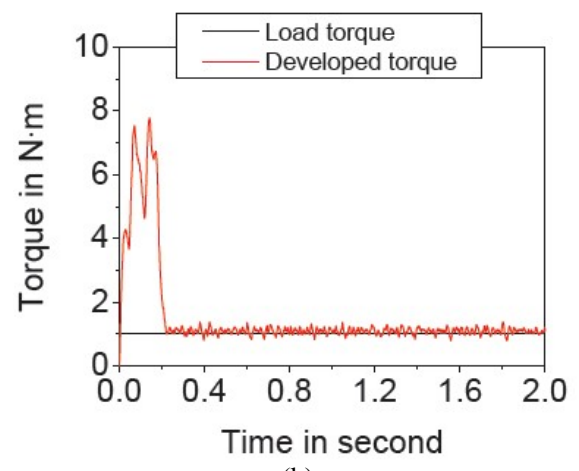

(b)

Fig. 6 (a) Simulated speed response, (b) Developed electromagnetic torque under transient and steady-state conditions.

\section{Performance under Different Operating Conditions}

1) Sudden Change of Load Torque

The motor was started from standstill condition with load torque $1.0 \mathrm{~N} \cdot \mathrm{m}$. Suddenly at $\mathrm{t}=1.0 \mathrm{~s}$ load torque is increased to $4.0 \mathrm{~N} \cdot \mathrm{m}$. The developed electromagnetic torque and speed response with change of load at $\mathrm{t}=1.0 \mathrm{~s}$ is given in Figs. 7(a) and (b). Sudden application of load torque causes a negligible oscillation in speed. The steady-state error is almost negligible.

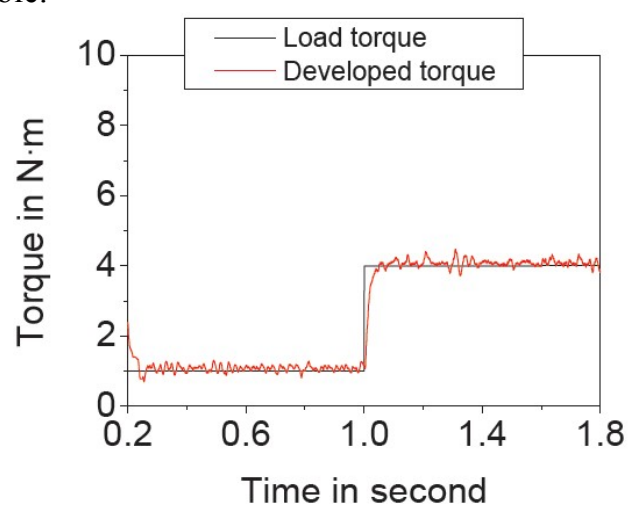

(a)

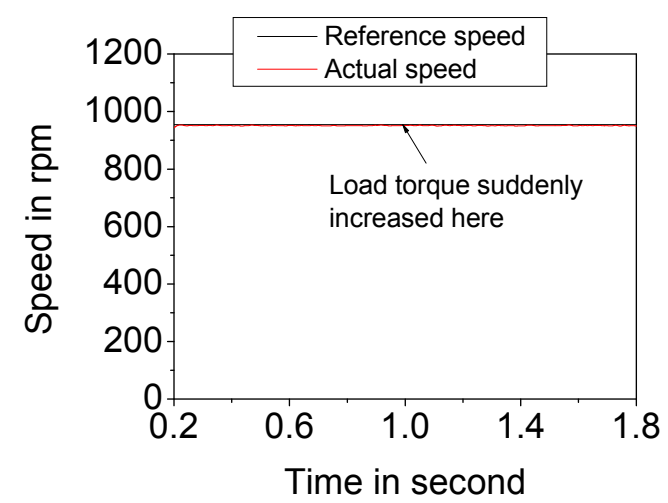

(b)

Fig. 7 (a) Developed electromagnetic torque, (b) Simulated speed response for the IPMSM drive for change of load torque $(1.0 \mathrm{~N} \cdot \mathrm{m}$ to $4.0 \mathrm{~N} \cdot \mathrm{m})$.

\section{2) Variation of Stator Parameters}

The effect of mismatch in the value of stator resistance on angle estimation was studied by increasing it to double its 
nominal value suddenly at $\mathrm{t}=0.25 \mathrm{~s}$. Fig. 8 (a) shows the effect of stator resistance change on angle estimation. The estimated angle still follows the actual angle. Thus the change in resistance has negligible effect on the accuracy of rotor position estimation. Fig. 8(b) shows the effect of stator inductance change on angle estimation. The d- and q-axis inductances are doubled at $\mathrm{t}=0.25 \mathrm{~s}$. It is noted that change in inductances does not affect the rotor position estimation. Thus the drive performance is insensitive to stator parameter variation.

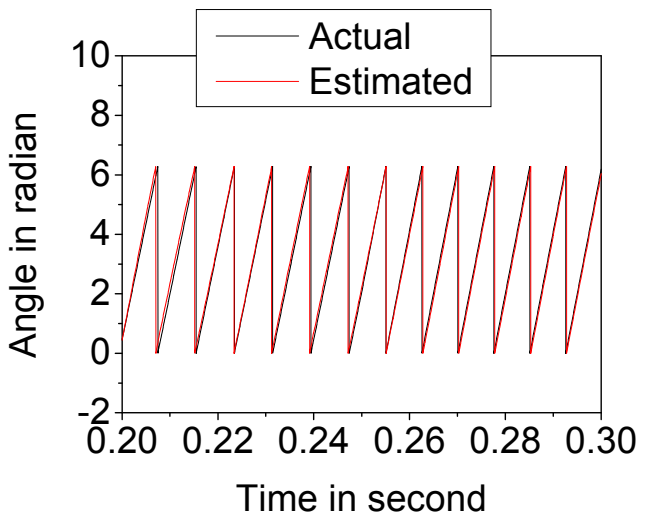

(a)

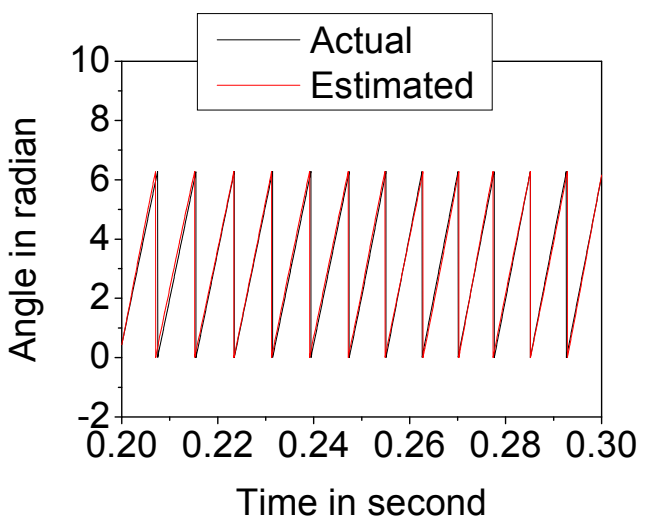

(b)

Fig. 8 Estimated and actual rotor angle for the IPMSM drive for change in (a) stator resistance ( $\mathrm{R}$ to $2 \mathrm{R}$ ) (b) stator inductances ( $\mathrm{Lq}$ to $2 \mathrm{Lq}$ and $\mathrm{Ld}$ to $2 \mathrm{Ld}$ ).

\section{3) Reversal of Speed}

Fig. 9(a) shows the speed response for reversal of speed. It is observed that the drive system follows a very fast speed response and takes almost double time when the speed is reversed from $+955 \mathrm{rpm}$ to $-955 \mathrm{rpm}$ or vice versa in comparison to starting condition $(0$ to $+955 \mathrm{rpm})$. Fig. 9 (b) shows corresponding developed electromagnetic torque.

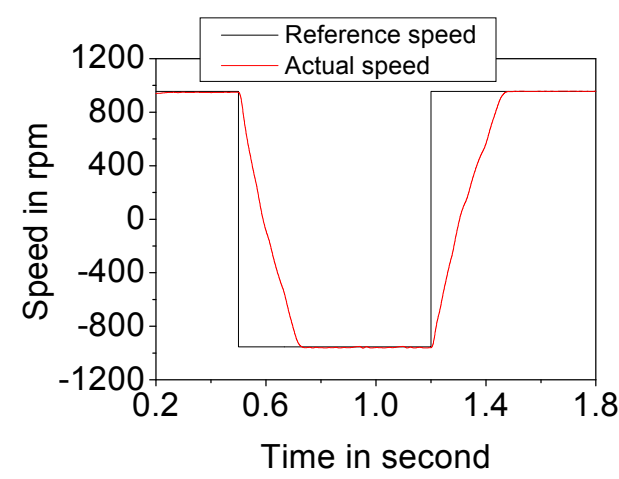

(a)

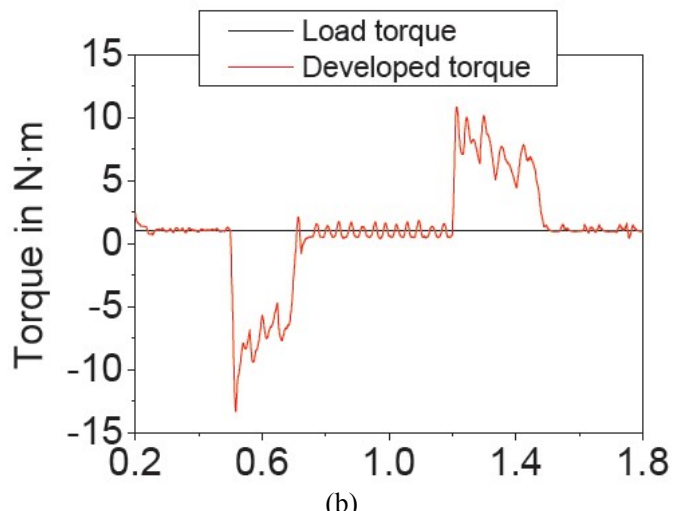

Fig. 9 (a) Simulated speed response and (b) Developed electromagnetic torque for the IPMSM drive for change in reference speed from $955 \mathrm{rpm}$ to $-955 \mathrm{rpm}$ and again to $955 \mathrm{rpm}$.

\section{CONCLUSION}

The control methodology proposed in this paper is found to work satisfactorily without any position sensor. It needs only a speed transducer and simple 3-phase voltage regulated SVM inverter. The RTRNN flux estimator is accurate and robust under parameter deviation conditions. The proposed control scheme is sufficiently stable and robust to load disturbances, and speed reversal. Very fast response of the system without oscillation indicates the effectiveness of the proposed control scheme.

\section{APPENDIX}

The motor parameters, PI gains and weights used in the system are summarized below:

Interior permanent magnet synchronous motor,

Rating: 3-phase, 1 hp, $300 \mathrm{~V}, 3 \mathrm{~A}, 50 \mathrm{~Hz}, 2$-pole pair.

Parameters:

Stator resistance, $\quad R=5.8 \Omega$

d-axis inductance, $L_{d}=0.0448 \mathrm{H}$

q-axis inductance, $L_{q}=0.1024 \mathrm{H}$

Motor inertia, $\quad J_{m}=0.0087 \mathrm{Kg} \cdot \mathrm{m}^{2}$

Rated torque, $\quad T_{b}=6 \mathrm{~N} \cdot \mathrm{m}$

Friction coefficient, $B_{m}=0.0008 \mathrm{Nm} / \mathrm{rad} / \mathrm{sec}$

Magnetic flux constant, $\psi_{f}(\mathrm{rms})=0.533 \mathrm{~Wb}$

Speed loop: $\mathrm{K}_{\mathrm{p}}=0.30, \mathrm{~K}_{\mathrm{i}}=0.016$

Weights of the RTRNN: $\mathrm{W}_{11 \mathrm{p}}=\mathrm{W}_{22 \mathrm{p}}=0.962, \mathrm{~W}_{11}=\mathrm{W}_{22}=$ $0.005, \mathrm{~W}_{12}=-\mathrm{W}_{21}=0.008, \mathrm{~W}_{13}=\mathrm{W}_{23}=0.0001$ 


\section{REFERENCES}

[1] B. K. Bose, "A High-Performance Inverter-Fed Drive System of an Interior Permanent Magnet Synchronous Machine," IEEE Trans. on Industry Applications, vol. 24, no. 6, Nov. /Dec. 1988, pp. 987-997.

[2] M. N. Uddin, T. S. Radwan, and M. A. Rahman, "Fuzzy-logic-controller-based cost effective four-switch three-phase inverter-fed IPM synchronous motor drive system," IEEE Trans. Industry Applications, vol. 42, no. 1, pp. 21-30, Jan. /Feb. 2006.

[3] M. N. Uddin, T. S. Radwan, and M. A. Rahman, "Performances of fuzzy-logic-based indirect vector control for induction motor drive," IEEE Trans. Industry Applications, vol. 38, no. 5, pp. 1219-1225, Sep./Oct. 2002

[4] M. N. Uddin, T. S. Radwan, G. H. George, and M. A. Rahman, "Performance of current controllers for VSI-Fed IPMSM drive," IEEE Trans. Industry Applications, vol. 36, no. 6, pp. 1531-1538, Nov. /Dec. 2000.

[5] B. K. Bose and P. M. Szczesny, "A Microcomputer- Based Control and Simulation of an Advanced IPM Synchronous Machine Drive System for Electric Vehicle Propulsion," IEEE Trans. on Industrial Electronics, vol. 35 , no. 4, Nov. 1988 , pp. 547-559.

[6] L. Chen, R. Davis, S. Stela, T. Tesch, and A. F. Antze, "Improved control techniques for IPM motor drives on vehicle application," in Conf. Rec. IEEE Industry Applications Society (IAS) Annu. Meeting, Pittsburgh, PA, 2002, pp. 2051-2056.

[7] D.Y. Ohm, J.W. Brown, and V.B. Chava, "Modeling and Parameter Characterization of Permanent Magnet Synchronous Motors," Proceedings of the 24th Annual Symposium of Incremental Motion Control Systems and Devices, San Jose, pp. 81-86, June 5-8, 1995.

[8] Kenji Nakamura, Kenichi Saito, and Osamu Ichinokura, "Dynamic analysis of Interior permanent magnet motor based on a magnetic circuit model," IEEE Trans. On Magnetic, Vol. 39, No. 5, September 2003, PP. 3250-3252.

[9] Satoshi Ogasawara and Hirofumi Akagi, "Implementation and position control performance of a position-sensorless IPM motor drive system based on magnetic saliency," IEEE Trans. on Industry applications, Vol. 34, No. 4, July/August 1998, pp. 806-812.

[10] Koji Tanaka and Ichiro Miki, "Position Sensorless Control of Interior Permanent Magnet Synchronous Motor Using Extended Electromotive Force," Electrical Engineering in Japan, Vol. 161, No. 3, 2007.

[11] Z. xu and M. F. Rahman, "Encoder less operation of a direct torque controlled IPM motor drive with a novel sliding mode observer," AUPEC, 26-29 September 2004.

[12] P.C. Krause, Analysis of Electric Machinery, McGraw-Hill, 1986.

[13] B.K. Bose, Power Electronics and Variable Frequency Drives, IEEE Press, 1997.

[14] Md. Abdur Rafiq, Mohammed Golam Sarwer, \& B.C. Ghosh, "Fast Speed Response Field-Orientation Control of Induction Motor Drive with Adaptive Neural Integrator," Istanbul University-Journal of Electrical \& Electronics Engineering, Vol. 6, No: 2, pp. 229-235, 2006. 